\title{
THE OCTOBER MEETING IN CAMBRIDGE
}

The six hundred eighty-eighth meeting of the American Mathematical Society was held at the Massachusetts Institute of Technology, Cambridge, Massachusetts, on Saturday, October 30, 1971. There were 89 registrants including 79 members of the Society.

By invitation of the Committee to Select Hour Speakers for Eastern Sectional Meetings, there were two invited addresses. Professor Barry Mazur of Harvard University spoke on Frobenius and the Hodge filtration; he was introduced by Professor Michael Artin. Professor Gerald E. Sacks of the Massachusetts Institute of Technology spoke on The differential closure of a differential field; he was introduced by Professor Arthur P. Mattuck.

There were four sessions for contributed papers, chaired by Professors Arshag B. Hajian, L. Aileen Hostinsky, Fred E. J. Linton, and Robert T. Seeley.

Middletown, Connecticut

WALTER GotTSCHALK Associate Secretary 